This is an Author's Accepted Manuscript of an article published in Davies, D, Collier, C and Howe, A (2012) A matter of interpretation: developing primary pupils' enquiry skills using position-linked datalogging. Research in Science \& Technological Education, 30 (3). pp. 311-325. ISSN 0263-5143 [copyright Taylor \& Francis], available online at: http://www.tandfonline.com/10.1080/02635143.2012.738420.

\title{
A MATTER OF INTERPRETATION: DEVELOPING PRIMARY PUPILS' ENQUIRY SKILLS USING POSITION-LINKED DATALOGGING
}

\begin{abstract}
This article reports on an evaluation study of a two-phase project involving 16 primary schools in England, seeking to develop the use of position-linked datalogging with pupils aged 9-10 years and hence improve their data interpretation skills. The study found that datalogging had become a regular feature of practical science in nearly all project schools up to 30 months after the end of the project, but that the use of position-linked logging had not been sustained. Whilst there is evidence of pupils developing a range of scientific enquiry skills through the project, the extent to which their interpretation of data improved is unclear. All participating schools made greater use of scientific data than before the project to develop their environmental education. These findings are discussed in relation to teachers' uptake of new technologies to support scientific enquiry; the relevance of data interpretation skills to pupils' scientific literacy; and the relationship between science and environmental education in primary schools.
\end{abstract}

\section{Introduction}

Position-linked datalogging is a technology which enables measurements of physical environmental factors - such as temperature, humidity, ambient light and sound levels - to be combined with global positioning satellite (GPS) data to map the variations of these conditions in time and space. It is widely used by environmental scientists and 
vulcanologists; for example to monitor the seismic shifts and temperature changes at various points on an active volcano to predict future eruptions. Versions of this technology are now available to schools, offering pupils the potential to collect data on local environmental conditions (temperature, humidity, air quality, light and sound pollution) and superimpose graphical representations of these data on web-based mapping tools such as Google Earth.

In a review of 61 empirical studies dealing with the efficacy of computer visualisations and simulations in science instruction, Smetana and Bell (2012) found that simulations can be as effective, and in many ways more effective, than traditional instructional practices in promoting science content knowledge and developing pupils' process skills. For example, Huppert et al. (2002) reported that secondary school pupils using a computer simulation to model a 'growth curve' of microorganisms achieved significantly higher test scores than their counterparts in a control group. Bilbokaite (2010) reported positive effects on girls' motivation of using computer visualisations in science lessons, whilst Lee et al. (2006) found that optimised visual displays promoted student comprehension and transfer of scientific concepts. Urhahne et al. (2009) concluded that three-dimensional computer simulations are more effective for younger students who lack the experience of learning with different visual representations. The use of web-based modelling software could also help pupils develop certain scientific enquiry skills, such as the manipulation of variables (Saat 2004).

The interpretation of scientific data has been argued to be a key component of developing scientific literacy (Collins et al. 2001). Primary-age pupils appear to find data interpretation one of the most difficult enquiry skills to develop (Watson et al. 1998). Swatton (1995) argues that 11-year olds find dealing with data in a mechanical way - i.e. reading or representing it as individual data points - easier than understanding what the data actually 
represent in terms of an underlying relationship between the variables. There is some evidence (Warwick \& Siraj-Blatchford 2006) that comparing experimental data pupils have collected themselves with other sources can enhance their motivation to provide explanations. This suggests that the use of a datalogger to produce graphs in 'real-time' as a science investigation proceeds should enable pupils to make links between the physical quantities they are measuring and the animated movements of graphical representation appearing onscreen, enabling the discussion of underlying relationships and remove the need to labour over the mechanics of graph plotting.

Whilst there is an extensive literature documenting the benefits of datalogging activities for enhancing secondary school pupils' experiences of scientific enquiry and their data interpretation skills (e.g. Newton 2000; Tan et al. 2006; Dixon 2008), very little has been published in the field of primary science, other than general advocacy and guidance (e.g. Warwick \& McFarlane 1998). Many primary schools in the UK possess datalogging equipment - for example every Scottish Borders primary school was provided with a datalogging kit and a folder of lesson plans and information in 2006 - but few teachers use them regularly (Murphy et al. 2007). Murphy (2003) argues that the potential value of using dataloggers and sensors in primary science is considerable in terms of the development of the skills of observation, measurement, experimenting, space-time relationships, interpreting data, inference and prediction, although she acknowledges the technical barriers nonspecialist teachers face in using such equipment with confidence.

One area of the curriculum where dataloggers could arguably make a considerable contribution is that of environmental science, where the benefits of being able to collect data on local environmental conditions (temperature, humidity, air quality, light and sound 
pollution) could enhance pupils' first-hand experience of intangible phenomena.

Environmental science - together with its variants such as education for sustainable development - has remained peripheral to statutory curricula in England (Elstgeest \& Harlen 1990; Littledyke 1997). This is associated with a lack of pupil awareness of sustainability concepts such as the difference between renewable and non-renewable resources (Summers and Kruger 2003), deforestation and global warming (Palmer and Suggate 2005). However, the growth of the 'Eco-Schools' movement (Mogensen \& Mayer 2005), with its associated registration and certification process, has increased awareness and activity in this area of the curriculum, with a majority of pupils aged 10-11 asserting that their own behaviour (e.g. recycling) and actions (e.g. writing a letter of protest) could make a difference (Palmer and Suggate 2005). Although the designation of Eco-Schools co-ordinators in many primary schools in England has gone some way towards providing the needed support for this area of the curriculum identified by Gough \& Sharpley (2005), the link with science has been largely absent (Mogensen \& Mayer 2005). This was one of the concerns that prompted the authors to develop the Eco-monitoring at Key Stage 2 Project.

\section{Project design}

The Eco-monitoring at Key Stage 2 project, on which this article reports, aimed to find out whether pupils in the 9-11 age range could make effective use of position-linked datalogging in their environmental science work. The authors worked closely with a local manufacturer of datalogging equipment to introduce this technology to primary schools in response to the following perceived needs:

- the under-development of primary-aged pupils' data interpretation and reasoning skills by comparison with other aspects of scientific enquiry; 
- the under-use of information and communications technology (ICT) - particularly datalogging - within primary science classroom practice;

- the schools' ambitions to achieve 'Eco-School' status by monitoring and reducing their carbon footprints (Eco-Schools is an international award programme);

- the growth in availability and increasing familiarity to children of GPS technology, thus providing a meaningful context for the introduction of position-linked datalogging.

The project used the software package JData3D - produced by ScienceScope Ltd. - which integrates data from GPS with sensor data collected outdoors to produce Google Earth visualisations of environmental quality in particular locations. These visualisations superimpose bar charts or line graphs of sound, temperature, light or various gas concentrations on aerial views of the area around which pupils have walked, providing them with visual cues to help them interpret these data - see Figure 1.

(Figure 1 near here)

The project took place in two phases: phase 1 involving 10 primary schools in the South West of England (2008-9) and a replication phase involving six primary schools in Greater London during 2010. Schools involved in the first phase of the project represented a range of urban, suburban and rural contexts from two local authorities, whilst those in the second phase were urban or suburban. In both phases, schools were selected from those where the science coordinator had previously participated in CPD activities led by the project co-ordinators and who had shown a particular interest in developing datalogging to support environmental education. It was decided to focus the project on pupils in the 9-10 age range since this was judged on the basis of previous experience in the project team to be the minimum age at which pupils could deal with the technical complexities of the equipment, whilst not being under the pressure of national testing at age 11. Although younger pupils used datalogging 
equipment successfully in the project schools, the JData3D interface - having been designed for secondary school use - was complex. All pupils in the specified age-range participated to some extent $(\mathrm{N} \approx 450)$ and each school identified a focus group of between two and four pupils $(\mathrm{n}=38)$ together with two members of staff to be more closely involved in the project.

In each phase, the participant teachers met with the project team on four occasions during the year for a full day of continuing professional development (CPD), planning and reflections on progress. In phase 2, each pair of teachers was joined by a pair of pupils from their school. This enabled these pupils to become experts in the use of the equipment (dataloggers, GPS receivers, cameras) and facilitated more rapid dissemination back in their schools through peer tutoring. They were also able to report back on their progress and findings at each CPD day. Between these dates participants remained in contact through a web forum and posted pupil work on a restricted-access website. Project team members visited each participating school on three occasions during the year to provide technical and pedagogical support, with frequent telephone and email contact.

Teachers and pupils from each participating school planned and executed their own ecomonitoring projects. Examples are given in the 'results' section below. Several of these projects were subsequently submitted as part of Eco-Schools accreditation. The dissemination event at the end of phase 1 took the form of an internally-organised 'Eco-monitoring Conference' at which pupils presented their findings to each other and invited guests. The phase 2 teacher participants presenting their findings at a national science education conference. 


\section{Evaluation research design}

Each phase of the project was evaluated independently against research questions drawn from the project aims:

RQ1. To what extent has participant teachers' confidence in using datalogging as an everyday part of their science teaching developed through the project?

RQ2. How has the project developed participant pupils' abilities to design datalogging investigations, collect relevant environmental monitoring data and interpret these and other environmental data?

RQ3. How has the project supported schools in their monitoring of environmental indicators in pursuance of Eco-School status?

The evaluation adopted a multi-method approach (Saxe \& Fine 1979; Bennet 2003).

Qualitative and quantitative data were collected from the following sources:

a) Documentary sources including printed project support materials produced as guides to teachers at the beginning of the project and during training days $(n=8)$; project data and findings posted by participant schools on a secure website $(n=16)$; school project plans and reports $(n=16)$.

b) Observations of CPD cluster days: the independent evaluators attended all training events in both phases of the project and made observation notes $(n=8)$.

c) Observation of dissemination events: the phase 1 mini conference was video-recorded $(\mathrm{n}=$ 9 presentations) and the evaluator attended the presentation given by phase 2 project teachers $(n=6)$ at the national science education conference.

d) Baseline pupil assessment task: at the beginning of phase 1, participant teachers were 
asked to devise their own ways of assessing pupils' baseline data interpretation skills ( $\mathrm{n}=$ 246 pupils). Whilst this approach gave participant teachers ownership of the assessment process - enabling them to select strategies which they felt suited their pupils - it created problems in comparing findings between schools. For this reason, in phase 2 we prescribed a baseline assessment task to be carried out by participant teachers in their schools $(n=45$ returns).

e) Teachers' baseline questionnaire: Participant teachers were asked to complete an initial questionnaire to provide information about school ICT facilities and their attitudes towards the use of ICT to support scientific enquiry $(n=25)$.

f) Classroom observations. The evaluators observed eco-monitoring activities in eight schools (four in each phase). Photographic $(\mathrm{n}=168)$ and video $(\mathrm{n} \approx 4$ hours $)$ evidence were also collected during these visits.

g) Samples of pupil work including group project reports, annotated graphs, Google Earth visualisations and maps from four phase 2 primary schools $(n=31$ samples $)$.

h) End-of-project pupil assessment: the baseline data interpretation assessment tasks described above were repeated with focus pupils at the end of each phase of the project $(\mathrm{n}=$ 38) .

i) Teachers' and pupils' responses to the project: phase 1 teachers repeated the baseline questionnaire and completed an evaluation form $(n=14)$, whilst phase 2 teachers participated in a focus group interview at the end of the project $(n=6)$. A pupil evaluation form was completed by those attending the phase 1 dissemination event $(n=24)$, whilst in phase 2 teachers undertook whole-class interviews to elicit pupils' perspectives on the project $(\mathrm{n} \approx$ 100). Upon reflection, a pupil focus group interview may have provided richer data.

j) Longitudinal evaluation: six schools were revisited 30 months after the end of phase 1 and a further focus group interview was conducted with teachers from five schools 12 months 
after the end of phase 2, to elicit participant teachers' perspectives on the longer-term impact of the project.

The evaluators entered the quantitative data from questionnaires and pupil assessment on Excel spreadsheets and produced descriptive summary statistics (frequencies and percentages, mean score differences). Qualitative interview, observation, video, documentary and questionnaire data were transcribed, coded against themes derived from the research questions and triangulated against each other and the quantitative data to check for corroboration. Table I summarises the triangulation process. Evaluation findings were checked with participant teachers and project leaders to provide respondent-confirmed validity (Morse et al. 2002).

(Table I near here)

\section{Results}

Findings below are summarised under headings drawn from evaluation research questions. RQ2 has been broken down into two sections in order to report separately on pupils' development of data interpretation skills.

\section{Participant teachers' confidence with using datalogging}

From the Teachers' baseline questionnaire (data source e), it appears that the majority of participating schools had access to between one and five dataloggers before the start of the project, although four respondents reported that they had none. This may genuinely have been the case, or an alternative explanation might have been that they did not personally know of any. In the phase 1 schools, a large majority (75\%) stated that they either 'never' used them, or did so 'less than once a year', whilst for phase 2 there was a wide range of 
frequency of use from 'weekly' to 'not really at all'; however termly or yearly appeared more common. The comments of two teachers during the in-school interviews illustrated the lack of confidence which may have led to this low frequency:

'Children weren't using dataloggers in their science. We had dataloggers in school but staff didn't feel confident... I've never been exposed to how I could use dataloggers effectively in a lesson.' (participant teachers, phase 2)

As evidenced in observations of CPD cluster days (data source b), in schools (source $f$ ) and at dissemination events (source c) all of the project teachers now have sustained practical experience of datalogger use. From the post-project questionnaire (source i) $85 \%$ of phase 1 teachers agreed or strongly agreed that they had become more confident with the use of datalogging through the project, although a majority felt that managing the activities in school was problematic to some or other degree, and that this had added to their workload. All teachers in the phase 2 focus group interview (source i) agreed that their confidence had risen considerably. This was partly ascribed to the development of the user interface on the dataloggers used during the project, which had led them to see many more possibilities for the use of the technology than science lessons alone. The following response was typical:

'Because they're easier to use you start to think of other places to use them - making cross-curricular links, like local area in geography, graphs in maths, local environment in PSHE.' (participant teacher)

The reasons behind this increase in confidence were ascribed to the way in which the project had been structured, involving the development of a datalogging community amongst the teachers and involving pupils from the start as peer-tutors. However, there were some aspects of datalogger use - downloading data and particularly the use of position-linked datalogging 
which continued to cause anxiety. 12 months on from the end of phase 2, all five schools represented in the focus group (source $\mathrm{j}$ ) reported regular use of datalogging, although without combining it with GPS technology. 30 months on from the end of phase 1, five of the six schools visited (source $\mathrm{j}$ ) were continuing to make regular use of datalogging to support scientific enquiry, whilst the teacher questioned in the sixth school was continuing to use Google Earth to help pupils visualise spatial distribution of environmental factors.

\section{Participant pupils' abilities to design datalogging investigations and collect relevant environmental monitoring data}

Many examples of pupils designing and carrying out their own eco-monitoring investigations were observed during classroom visits (source f), evidenced in pupil work (source g) or demonstrated through the high quality of their presentations at the phase 1 dissemination event (source c). For example, pupils in one school planned to monitor temperature, carbon monoxide and carbon dioxide levels around a local city, resulting in posters being produced to persuade fellow pupils and parents to reduce emissions. In another school pupils decided to measuring carbon dioxide levels in the classroom at different times of the day and under different conditions (e.g. leaving windows open or extraction fans on), evaluating the effectiveness of different approaches in lowering carbon dioxide levels. In a third school pupils decided to measure the impact of a 'switch-off' campaign on light and temperature levels around the school, and the school's electricity bills. Pupils in a fourth school worked with a nearby conservation organisation to study the impact of position, vegetation and depth of water on water temperature and wildlife diversity in several local ponds. In another school, pupils decided to measure carbon monoxide emissions from teachers' cars and use their analysis of data to make recommendations for 'greener' forms of transport to school. In one of the other schools, pupils designed an investigation to assess the effectiveness of 
movement-sensitive sensors to reduce light levels and power usage in unused classrooms.

According to the teachers in the focus-group interview following phase 2 (source i) the use of dataloggers in the project had stimulated questioning leading to investigation. The following comment was typical:

'The dataloggers enabled the children to carry out more ambitious investigations where they don't know the answers already!' (participant teacher)

Data from pupil classroom discussions at the end of phase 2 (source i) corroborates the above data. All pupils agreed that the use of dataloggers had helped them to come up with a question to investigate and collect the data easily in a form they could then interpret. Once pupils had become familiar with their use, they appreciated this way in which ICT could support science and the many ways in which they could use dataloggers for other investigations. Classroom observations (source f) suggest that whilst designing their investigations, pupils demonstrated awareness of how differences in datalogger readings between different conditions could provide them with useful information. For example, during a group discussion to plan an investigation into whether it was necessary to keep classroom lights on, one pupil made the following contribution:

'Say if we measured the light level then turned the light off we could see the difference. If there's a big difference we know we need the lights on. Maybe we should go to different positions to take snapshots.' (pupil contribution to project planning discussion)

Classroom observations also demonstrated pupils' understanding of 'fair-testing' in relation to when to take datalogger readings; whether to capture 'snapshot' or continuous data, and 
how reliability could be improved through taking repeat readings.

From the post-phase 1 pupil evaluation form and post-phase 2 classroom discussions (source i) all pupils in both phases agreed or strongly agreed that they had become more confident in using dataloggers to measure environmental factors. Because it was easier to capture accurate measurements, several pupils reported that they felt more like 'real' scientists. In relation to the measurement of sound levels, pupils reflected on the advantages of using dataloggers compared with their own ears in terms of reducing subjectivity, but could also comment on the limitations of their data when they realising that the sound sensor was only sensitive down to $50 \mathrm{~dB}$. At the phase 2 teacher focus group interview (source i), the practical challenges presented by some of the pupils' datalogging investigations were felt to have developed their problem-solving skills. The following comment was typical:

'The chance to think about what happens when things don't go right. They want to reattempt and re-do it, then being able to evaluate what happens and work on the fair test element.' (participant teacher)

\section{Pupils'abilities to interpret environmental data}

Results from the baseline (source d) and post-project tests designed to assess progress in pupils' data interpretation skills (source h) proved inconclusive, owing to low return rates and - in the case of phase 1 - non-comparable data sets. Although the CPD sessions had emphasised pupils' abilities to see patterns in data and link conclusions to evidence, most teachers chose to focus their baseline assessments upon a somewhat narrower set of graphreading skills. For example, the teacher in one phase 1 school gave graph interpretation exercises to his class both before and after the eco-monitoring activities. However, for the baseline, children were given a paper-based task to extract simple information from a bar 
chart. The final assessments involved interpreting a line graph of data obtained from Science Scope's Datadisk software; a task which, whilst drawing upon a wider set of interpretation skills, was not directly comparable with the baseline test . The teacher's analysis of his pupils' progress measured against National Curriculum levels shows a significant improvement from the baseline for the class overall (Table II).

(Table II near here)

In another school, 20 out of 28 pupils' grades went up by an average of one National Curriculum level in the nine-month project period (which is estimated by the UK government to represent, on average, two years' progress). However, in a third school, $45 \%$ of pupils made progress in data interpretation whilst the remaining 55\% did not. Other test data are similarly inconclusive; however there is qualitative evidence of pupils' developing abilities to make sense of data presented graphically, for example in the improved quality of the annotations made by them on bar charts and line graphs (source g). Pupils were also observed making perceptive comments when discussing the graphs in groups during school visits (source f), linking the readings they had taken to the physical phenomena being investigated. The following comments were typical:

'With the lights off it's still got some light but it's quite a big difference.'

'That's not what I expected; that just shows that there's not much difference (in carbon monoxide emission) between the older and newer cars.' (pupil comments during discussion of graphs)

In phase 2, the baseline and final assessment test focused upon reading a line graph; drawing conclusions linking a dependent variable (datalogger reading) and an independent variable; and explanation of data patterns in terms of scientific understanding.Teachers in the focus group (source i) agreed that the use of dataloggers had helped pupils to understand graphs, 
because they had the experience of seeing instantaneous changes in 'real time'. This was supported by the pupils' comments in the end-of-project school discussions (source i). All of the questioned pupils in one school agreed that having a graph produced on screen helped them to understand what a graph would "look" like before they came to do their experiment.

There is evidence from pupil work (source g) that they began to engage with some quite complex issues in relation to data reliability and its representation, such as anomalies and graph scales. Pupils from one phase 2 school agreed in the end of project discussion (source i) that the graphs from the datalogger were easy to compare, although they realised they needed to look carefully at the scales being used as sometimes apparently similar graphs had different scales:

'It was hard to compare them a hundred per cent accurately because the scales were sometimes different.' (participant pupil)

Teachers in the phase 2 focus group (source i) related this increasing sophistication to the fact that pupils had collected and presented the data themselves, allowing those with 'good scientific brains' but limited mathematical skills to go further in a science lesson than they might have managed without the dataloggers. They also felt it was valuable for pupils to learn about specialised units of measurements such as lux and parts per million (ppm), although responses from the pupils indicated that they found this aspect more challenging. There is however evidence of pupils developing confidence in exploring the implications of their data. According to teachers in one school, eco-monitoring had inspired an analytical approach to environmental data presented in the media. The following comment was typical: 
'It's caused them to think more closely about what's causing this. Why is it higher in certain places? What other factors affect the emissions... wanting to delve into it more.' (participant teacher)

\section{Support provided to schools in their monitoring of environmental indicators in pursuance}

\section{of Eco-School status}

There is good evidence from observations of the school project presentations at the phase 1 dissemination event (source c) - together with reports from classroom observations (source f) - that teachers and pupils had pursued the monitoring of environmental indicators in considerable depth. Some chose to monitor environmental parameters within the school premises themselves, while others ventured out into the local area to measure aspects such as noise from traffic. Three schools achieved Eco-Schools Bronze award during the project and a further four achieved Silver award. One school achieved both levels between March and July 2009. Another already had their Green Flag (highest award), but had subsequently used the monitoring of light levels in the playground to win a grant for a shady pergola (source j); a proposal described by the charitable awarding body as the strongest they had received in 15 years.

At the phase 2 teacher focus group interview (source i) all agreed that the eco-monitoring project had made a positive impact upon their school's environmental education and the ways pupils behaved in relation to environmental issues. The following comment was typical:

'It's definitely raised all the children's awareness of environmental issues - turning lights out, closing doors. Seeing their peers going round measuring, seeing the evidence.' (participant teacher) 
For some teachers in the focus group, the local emphasis within the project had neglected to link environmental issues together for pupils, in terms of considering human impact upon the World as a whole. However, for others, the practical nature of the activity was what made environmental issues come to life for pupils. From the longitudinal visits (source j) all the schools reported that the project had given environmental science a much-needed boost, whilst the eco-monitoring activity was commended by school inspectors in one school because it was practical and made good use of the school grounds.

\section{Discussion}

Several themes emerge from the findings above, including the factors leading to uptake of new technologies by teachers to support scientific enquiry; the relevance of data interpretation skills to pupils' development of scientific literacy and the relationship between science and environmental education in primary schools.

\section{Uptake of new technologies to support scientific enquiry in primary schools}

The baseline data concerning primary teachers' lack of confidence in their use of datalogging equipment collected during this study concurred with findings from Murphy et al. (2007); despite such equipment being widely available in UK primary schools for the past two decades and a statutory part of both science and ICT programmes of study in the National Curriculum for England (DfE/QCA 1999), uptake has largely been restricted to 'enthusiasts' who, when they move schools, leave their non-specialist colleagues with a resource which remains in a cupboard. Whilst the Eco-monitoring at Key Stage 2 project led to wide-spread use of datalogging in participant schools, this may be attributed to a Hawthorne effect (Landsberger 1958). What is arguably more significant is that such practice was still 
widespread up to 30 months after the end of the project, suggesting that it had become embedded in classroom practice, at least to some extent. The factors leading to this appeared to have been the regular, routine use of datalogging in project classrooms - leading to familiarity, habituation and an awareness of pros and cons - and the ownership given to pupils (particularly in project 2).

Part of the reason for primary teachers' reluctance to include datalogging and other forms of new technology in their science teaching may be a lack of awareness of its 'affordances' (Gaver 1991) to support the development of scientific skills and thinking. There is evidence from the above findings that using dataloggers facilitated pupils' data collection and presentation (Webb 2005) and enabled them to make links between data and real-world contexts (Huppert et al. 2002). Project teachers' growth in awareness of the potential of datalogging activities expressed during focus group interviews echoed some of the points put forward by Murphy (2003), whilst they continued to express anxiety at the technical barriers presented by the integration of GPS data. Indeed, the position-linked element of datalogging practice was least in evidence from the longitudinal findings, suggesting that this element was either too novel or not-yet sufficiently user-friendly to be used on a regular basis. The limitation of GPS use to outdoors was another factor tending to limit its use, since it both restricted the range of investigations which could be undertaken and created supervision difficulties for teachers whose practice was primarily classroom-based.

\section{Relevance of data interpretation skills to pupils' scientific literacy}

Millar \& Osborne (1998) argue that citizens in a democracy need to be able to interpret scientific information presented in the media in order to make everyday decisions that affect their lives, and that this justifies the inclusion of science in the school curriculum. However, 
data interpretation is a 'higher order process skill' (Harlen, 1996) which is hard for primaryaged pupils to develop (Watson et al. 1998). There is evidence from the findings above that the use of datalogging - particularly when integrated with GPS tracking to produce visualisations on Google Earth - has helped pupils develop their skills in this area, as claimed by Dixon (2008). Clearly, the removal of the requirement to manipulate data and construct graphs enabled participants to interact with the meanings behind the data more fundamentally, as suggested by Swatton (1995). However, the inconclusive results from the pupil assessment suggest that they may continue to have difficulty in applying a skill they have developed in a practical context to the more abstract process of making sense of data collected by others.

Together with the difficulties of transferring 'situated' skills from the experimental domain to the 'real world' context (Lave \& Wenger, 1991), the extent to which developing such skills is fundamental to scientific literacy could be questioned. For example, pupils in one project school became adept at interpreting line graphs of carbon dioxide concentration in their classroom, only to propose solutions which would increase the school's carbon emissions, such as opening windows or installing air conditioning. They had confused the microcarbon dioxide in the classroom - with the macro - carbon dioxide in the atmosphere - and it could be argued that the focus upon data interpretation had prevented them from seeing the bigger picture. Scientific data relating to environmental issues tends to be highly complex and open to a range of interpretations. Perhaps a more relevant process skill for pupils to develop is the ability to weigh up scientific arguments and be able to take a wider perspective on issues rather than a narrow focus on the interpretation of graphs. 


\section{The relationship between science and environmental education in primary schools}

The focus on environmental issues within the project schools, together with the time allocated for both science and Eco-Schools co-ordinators to develop monitoring projects contributed towards the conditions identified by Gough \& Sharpley (2005) for embedding environmental science in the curriculum. However, the technical difficulties encountered by teachers in using the GPS technology in combination with datalogging - arguably the application of most value in monitoring environmental data around the school - raise some questions for the longer term integration of science within environmental education, a danger highlighted by Littledyke (1997). Longitudinal visits to the schools in January 2012 suggested that whilst datalogging was continuing to be used for general experimental science, it was not being used to monitor environmental data and position-linked datalogging had ceased. Schools were continuing to highlight environmental issues, but not linking these with scientific data.

Despite the complexities and difficulty of interpretation referred to above, if environmental education is not underpinned by scientific data and argument it will continue to be marginal to the school curriculum (Littledyke 1997). Science, whilst declining in status in the primary curriculum of England in recent years, can still be argued to be a key component of such a curriculum (Harlen, 2008), so only by aligning itself with science can environmental education seek to improve its status (Goodson, 1987). The requirement for schools seeking Eco-Schools Silver Award and above to submit locally-collected data in support of their application (Mogensen \& Mayer, 1987) is welcome in this respect. Although several of the schools in the Eco-monitoring at Key Stage 2 project used position-linked datalogging to collect such data, it would appear from the subsequent lack of use of such technology that it can only ever be part of the solution. However, as referred to in the introduction, it is widely used by climate scientists, so perhaps with future improvements in the reliability and ease of 
use of position-linked datalogging in schools its potential for enhancing environmental education will be realised.

\section{Conclusion and implications for further research}

The potential of combining datalogging with GPS technology to support challenging, motivating and relevant scientific enquiry has been demonstrated in principal by the Ecomonitoring at Key Stage 2 project. A total of around 480 pupils in 16 schools have experienced position-linked datalogging and its compelling Google Earth visualisations of locally-collected environmental data through the project, with some evidence of development of scientific enquiry skills including the 'higher order' process skill of interpretation. The 32 participating teachers have also increased their confidence in using the affordances of datalogging as an everyday tool to support scientific investigations. There are messages here for the types of CPD required by primary teachers to embed ICT within their science teaching: it needs to include regular periods of instruction and meaningful classroom-based tasks that require participants to use the new technologies regularly.

There are also implications from this study for future research in this area. If some of the technical and interface-related issues with position-linked datalogging can be made easier for primary teachers, will its use in schools be sustained to the same extent as the more basic datalogging has in this project, or is the requirement to be outdoors too great a barrier? Future research could also collect more robust data on the development of pupils' interpretation skills than was achieved in this study. Linking such skills to the development of scientific argumentation around environmental issues could also help build a stronger case for the development of scientific literacy through such activity. Finally, wider-ranging research concerning the potential for embedding scientific enquiry within environmental education in 
the primary curriculum would also be of value.

\section{References}

Bennet, J. (2003) Evaluation Methods in Research. London: Continuum.

Bilbokaitc, R. (2010) Use of visualization to motivate science and geography education of female schoolchildren. Problems of Education in the 21st Century 24: 49-57.

Collins, S., Osborne, J., Ratcliffe, M., Millar, R. and Duschl, R. (2001). What 'ideas about science' should be taught in school science? A Delphi study of the expert community. Paper presented at Annual Conference of the American Educational Research Association (AERA), 11-14 April, in Seattle, WA.

Dixon, N. (2008) Can data logging improve the quality of interpretation and evaluation in chemistry lessons? School Science Review 89(329): 55-62.

Elstgeest, J. and Harlen, W. (1990) Environmental Science in the Primary Curriculum. London: Paul Chapman.

Gaver, W. (1991) Affordances of technology. In Proceedings of the SIGCHI conference on Human factors in computing systems: Reaching through technology, ed. S. Robertson, G. Olson \& J. Olson, 79-84. New York: Association for Computing Machinery,

Goodson, I. (1987) School Subjects and Curriculum Change, 3rd Edn. London: Falmer.

Gough, A. \& Sharpley, B. (2005) Toward Effective Teaching and Learning: stories of primary schools' environmental science interest and action. Educational Action Research 13(2): $191-212$.

Harlen, W. (1996) The Teaching of Science. London: David Fulton Publishers.

Harlen, W. (ed.) (2008) Science as a Key Component of the Primary Curriculum: A Rationale with Policy Implications. Perspectives on Education 1 (Primary Science). London: Wellcome Trust. 
Huppert J., Lomask, S. M., \& Lazarowitz, R. (2002) Computer simulations in the high school: students' cognitive stages, science process skills and academic achievement in microbiology. International Journal of Science Education 24 (8): 803-821.

Landsberger, H.A. (1958) Hawthorne Revisited: Management and the worker. New York: Ithaca Press.

Lave, J. \& Wenger, E. (1991) Situated Learning. Legitimate peripheral participation. Cambridge: University of Cambridge Press.

Lee, H., Plass, J. and Homer, B. (2006) Optimizing Cognitive Load for Learning from Computer-Based Science Simulations. Journal of Educational Pysychology 98(4): $902-$ 913.

Littledyke, M. (1997) Science education for environmental education? Primary teacher perspectives and practices. British Educational Research Journal 23(5): 641-659.

Millar, R. \& Osborne, J. (1998) Beyond 2000 - Science Education for the Future. London: King's College.

Mogensen, F. \& Mayer, M. (eds.) (2005) ECO-schools: trends and divergences. A comparative study on ECO-school development processes in 13 countries. Vienna: Austrian Federal Ministry of Education, Science and Culture.

Morse, J. M., Barrett, M., Mayan, M., Olson, K. \& Spiers, J. (2002) Verification Strategies for Establishing Reliability and Validity in Qualitative Research. International Journal of Qualitative Methods 1(2): article 2. http://www.ualberta.ca/ iiqm/backissues/1_2Final/pdf/morseetal.pdf.

Murphy, C. (2003) Literature Review in Primary Science and ICT, FutureLab Series report 5. Futurelab. http://www2.futurelab.org.uk/resources/documents/lit_reviews/Primary_Science_Revie w.pdf. 
Murphy, C., Neil, P. \& Beggs, J. (2007) Primary science teacher confidence revisited: ten years on. Educational Research 49 (4): 415-430.

Newton, L. R. (2000) Datalogging in practical science: research and reality. International Journal of Science Education 22(12): 1247-1259.

Palmer, J. and Suggate, J. (2005) Children's reasoning about global environmental issues: deforestation and global warming. Primary Science Review 87: 12-16.

Saat, R. M. (2004) The acquisition of integrated science process skills in a web-based learning environment. Research in Science \& Technological Education 22(4): 23-40.

Saxe, L. \& Fine, M. (1979) Expanding our view of control groups in evaluations. In Improving Evaluations, eds. L. E. Datta \& R. Perloff. Beverley Hills, Calif.: Sage.

Smetana, L. K. \& Bell, R. L. (2012) Computer Simulations to Support Science Instruction and Learning: A critical review of the literature. International Journal of Science Education 34(9): 1337-1370.

Summers, M. and Kruger, C. (2003) Teaching Sustainable Development in Primary Schools: theory into practice. The Curriculum Journal 14(2): 157-180.

Swatton, P. (1995) Pupil performance in data manipulation and its relationship to the skill of interpretation. Educational Review 47(1): 43-56.

Tan, K. C. D., Hedberg, J. G., Thiam, S. K. \& Whye, C. S. (2006) Datalogging in Singapore schools: supporting effective implementations. Research in Science \& Technological Education 24(1): 111-127.

Urhahne, D., Nick, S. \& Schanze, S. (2009) The Effect of Three-Dimensional Simulations on the Understanding of Chemical Structures and Their Properties, Research in Science Education 39(4): 495-513.

Warwick, P. \& McFarlane, A. (1998) Datalogging in the Primary School. Leicester: SCICentre. 
Warwick, P. \& Siraj-Blatchford, J. (2006) Using Data Comparison and Interpretation to Develop Procedural Understandings in the Primary Classroom: Case study evidence from action research. International Journal of Science Education 28(5): 443-467.

Watson, J.R., Goldsworthy, A. \& Wood-Robinson, V. (1998) Getting AKSIS to Investigations. Education in Science 177: 20-21.

Webb, M.E. (2005) Affordances of ICT in science learning: implications for an integrated pedagogy. International Journal of Science Education 27(6): 705-735. 